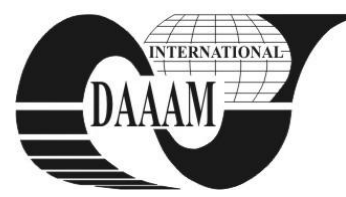

\title{
MARKETNET - AN INTERNET BASED MARKETING RESEARCH MODEL FOR STUDYING MARKETING NEEDS OF COMPANIES
}

\author{
EDU, T[udor] M[ihai]; NEGRICEA, C[ostel] I[liuta] \& ANICAI, O[vidiu]
}

\begin{abstract}
The purpose of this paper is to propose a comprehensive model based on secondary data which can be used by any company in an exploratory research to provide at least "first step" data about marketing needs in an industry. This model was conceived using a detailed marketing study guide and a consistent library of Internet-located data sources. Its purpose is to provide free and detailed findings, although not statistically relevant.
\end{abstract}

Key words: marketing, research, internet, secondary data

\section{INTRODUCTION}

The novelty of this model lies in the fact that it offers a free alternative for obtaining suitable data about marketing needs which usually are surveyed through direct research. The conclusions of a marketing research conducted based on our model can be used for making business decisions or they can be used to design a more detailed research.

The secondary data already exist (Andrlic \& Budic). They were collected in research studies performed at a prior date (Kotler \& Keller, 2006). The secondary data are very useful, because they can provide meaningful insight on various matters. The conclusions drawn after analysing secondary data can be sufficient for the researcher (Keegan \& Green, 2005). If they are not sufficient, they can represent a starting point for further research studies, such as a focus group, an in-depth interview or a survey.

This model was conceived using a comprehensive marketing study guide and a consistent library of Internet-located data sources which have been compiled by the authors after conducting several online marketing studies (Catoiu \& Edu, 2009; Catoiu, Edu \& Negricea, 2011). Its purpose is to provide free and detailed findings, although not statistically relevant.

\section{OUR MODEL- STRUCTURE AND FEATURES}

Our model can be used easily by any company just by collecting data for each section of the study guide which is structured in 6 chapters covering the most important marketing areas of interests (Catoiu, et al., 2009): business/economic or company research, buying behaviour research, product research, price research, promotion research, distribution research.

Each chapter is structured in several sections covering the most relevant aspects. Also, a section named "other" was considered, for data which cannot be included in the pre-established sections.

The other part of the model comprises the data sources which are only Internet-based. We were able to group the wide variety of sources in 7 categories based on types of websites: specialised publications in marketing; specialised publications in economics; information provided by specialised institutions in consultancy and marketing research; information provided by individual marketing specialists; information provided by advertising agencies; information provided by the economic sections of the daily newspapers; job web sites.
We believe that the two parts of the model are inseparable and provide a suitable tool which renders not just free but also high quality data for wise marketing decisions.

\section{MODEL TESTING}

In order to test our model, we conducted a marketing research pursuing the identification of the marketing needs of the Romanian marketing companies. The gathering and analysis of data were performed between February $1^{\text {st }}, 2011$ and May $1^{\text {st }}, 2011$. We identified 290 relevant references in the 7 categories of the model. These references were used to classify the findings in accordance with the 6 chapters of the study guide.

To conclude upon the effectiveness of our model we will display the findings through charts showing the distribution of the collected data in the pre-established sections and the "other" section of each of the 6 figures of the study guide.

For "business/economic or company research", the sections are: Features of the industry/market and tendencies on it; Studies about acquisitions and diversification; Studies about market share; Studies about employees; Other

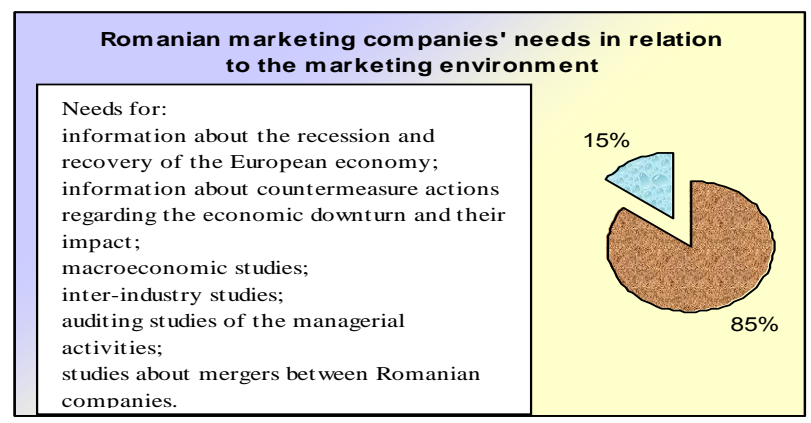

Fig. 1. Pre-established sections: $85 \%$; Other: $15 \%$

For "buying behaviour research", the sections are: Studies about brand preferences; Studies about attitude towards a brand; Studies about product satisfaction; Studies about buying behaviour; Studies about buying intentions; Studies about brand awareness; Segmentation studies; Other

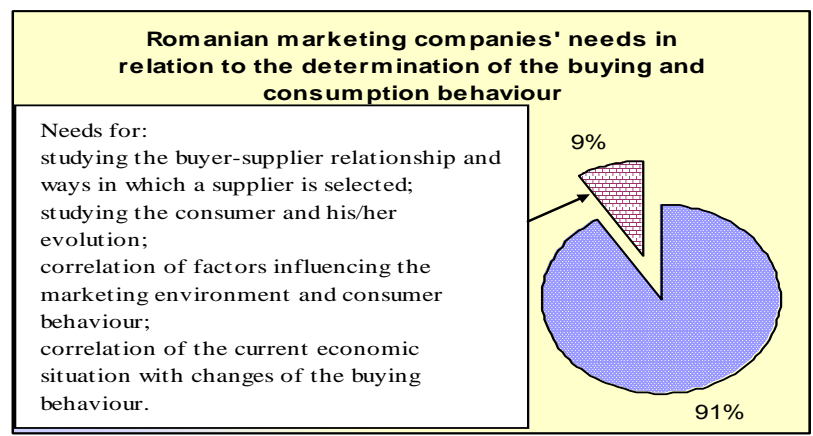

Fig. 2. Pre-established sections: 91\%; Other: $9 \%$ 
For "product research", the sections are: Information about concept development and testing; Information about brand name generation and testing; Information about a test market; Information about product testing; Information about package design; Information about competitor's products; Other

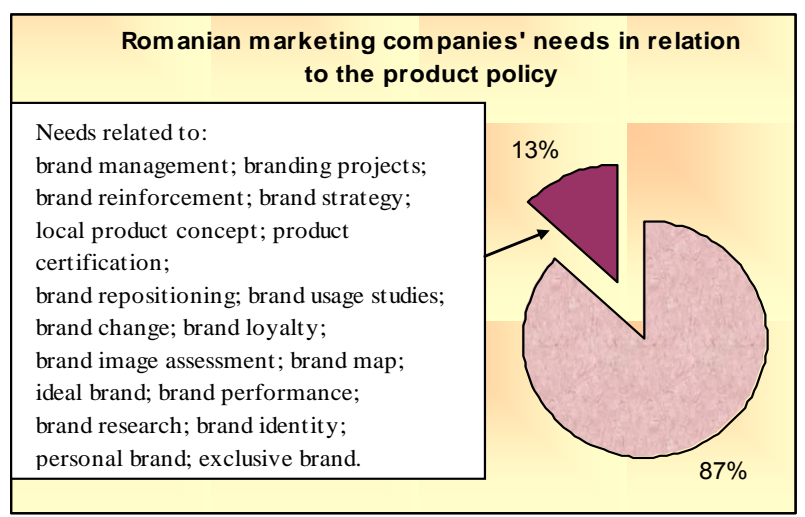

Fig. 3. Pre-established sections: $87 \%$; Other: $13 \%$

For "price research", the sections are: Information about cost analysis; Information about profit analysis; Information about price flexibility; Information about demand analysis: market potential; sales potential; sales forecasting; Information about competitors' price analysis; Other

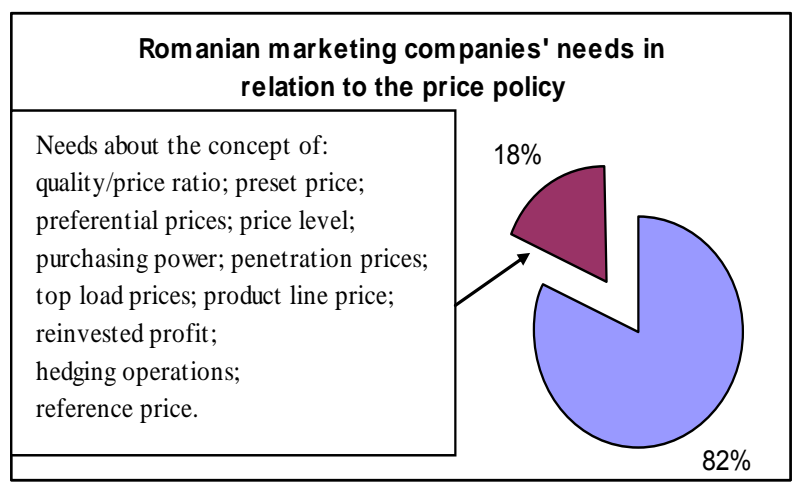

Fig. 4. Pre-established sections: $82 \%$; Other: $18 \%$

For "promotion research", the sections are: Studies about the motives which determine the choice for a means of communication; Studies about the mass communication means; Studies about the advertising message; Studies about the advertising efficiency: before/after broadcasting; Studies about the competitors' advertisements; Studies about the public image; Studies about the sales force's compensation; Studies about the sales force's shares; Studies about the sales force's areas; Other

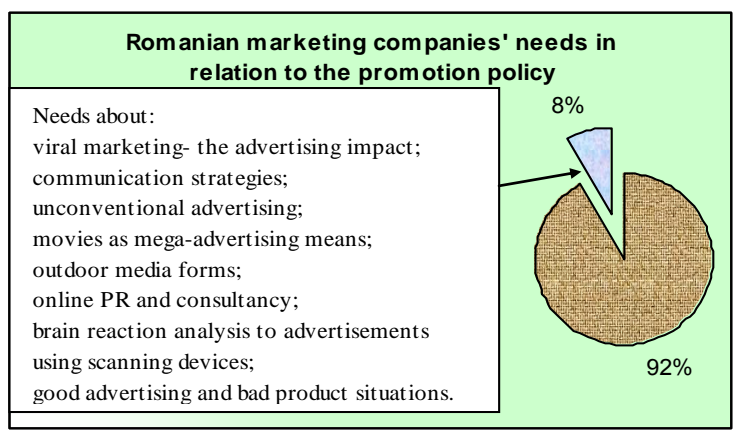

Fig. 5. Pre-established sections: 92\%; Other: $8 \%$
For "distribution research", the sections are: Studies about office/factory/warehouse location; Studies about distribution channel's performance; Studies about distribution channel's coverage; Studies about exports and international trade; Other

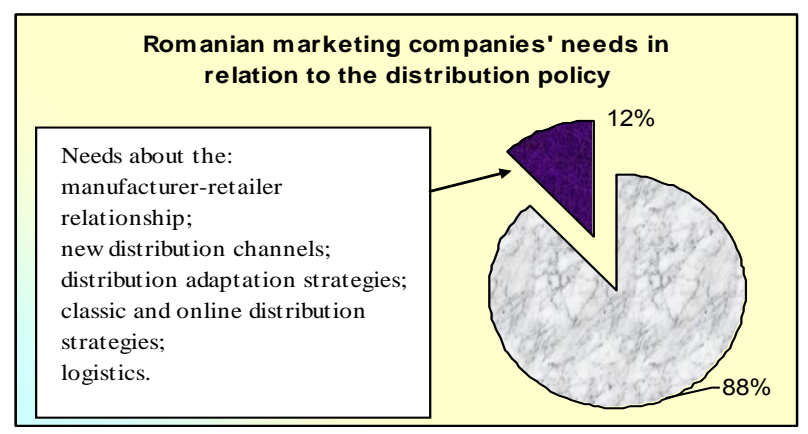

Fig. 6. Pre-established sections: $88 \%$; Other: $12 \%$

\section{CONCLUSIONS}

According to these statistics we can say that the model proved its effectiveness. The greatest part of the collected data was allocated in the pre-established sections of the 6 chapters. It is clear that it is not a perfect model but a perfectible one. It is impossible to develop a model to comprise all possible situations. In order to overcome this limitation, considered by the authors to be the only one significant, we included the section "Other" in each chapter to insert any data not related to the pre-established sections.

The fact that it does not involve any financial constrains and that it can be used in any industry to obtain suitable answers necessary to make marketing decisions, we strongly consider this model to be a suitable marketing tool for any company.

For the future, we plan to conduct several studies in different industries in order to test and improve our model by adapting it to the findings without losing the focus of being a general model and not a specific one for a particular industry.

\section{REFERENCES}

Andrlic, B. \& Budic, H. (2010). Possibilities of Tourism Market Research via the Internet, Annals of DAAAM for 2010 \& Proceedings of the 21st International DAAAM Symposium, 20-23rd October 2010, Zadar, Croatia, ISSN 1726-9679, ISBN 978-3-901509-73-5, Katalinic, B. (Ed.), pp. 00790080, Published by DAAAM International Vienna, Vienna

Catoiu, I et al. (2009). Cercetari de marketing- Tratat. Ed. Uranus, ISBN 978-973-7765-70-3, Bucuresti

Catoiu, I. \& Edu, T. (2009). The Identification of the Romanian companies' marketing needs and means of communicationa marketing research. Annales Universitatis Apulensis Series Oeconomica, Vol. 2, No. 11, 2009, pp. 969-978, ISSN 1454-9409

Catoiu, I., Edu, T. \& Negricea I. C. (2011). The Identification of the marketing approaches used by the Romanian Internet Service Providers- a marketing research. $18^{\text {th }}$ International Economic Conference - IECS 2011 "CRISES AFTER THE CRISIS. INQUIRIES FROM A NATIONAL, EUROPEAN AND GLOBAL PERSPECTIVE", Proceedings of the $18^{\text {th }}$ International Economic Conference, Sibiu, Romania, ISBN 978-606-12-0139-6, pp. 31-41, Ed. ULBSIBIU, Sibiu

Keegan, W. J. \& Green, M. C. (2005). Global Marketing. $4^{\text {th }}$ ed., Pearson Prentice Hall, ISBN 0-13-196854-8, USA

Kotler, Ph. \& Keller, K. L. (2006). Marketing Management. $12^{\text {th }}$ ed., Pearson Education Inc, ISBN 0-13-145757-8, NJ 